\title{
Myelodysplastic Syndrome: An Egyptian Experience
}

Noha M. El Husseiny*, Shereef A. Mohamed and Mervat M. Mattar

Clinical Haematology Unit, Internal Medicine Department, Faculty of Medicine, Cairo University, Egypt

\section{Summary}

Background: Myelodysplastic syndromes (MDS) incidence is unclear because of historical lack of populationbased registration and possibly because of under diagnosis.

Purpose: To present some retrospective data on the epidemiology of Myelodysplastic syndrome (MDS) in Egypt, as reflected by a single centre which is the largest tertiary referral center of Haematology in Egypt.

Patients and Methods: Patients diagnosed with MDS and referred to Clinical Haematology unit of Internal Medicine Department Cairo University, Egypt between 2007-2010 were identified. Complete demographic and clinical data, laboratory results, treatment modalities were collected and analyzed.

Results: Sixty nine patients with MDS were identified. Thirty nine (57\%) females, thirty (43\%) male subjects. Mean age was 55 years. Nine (13\%) patients were positive for HCV. Mean ferretin level was $844 \mathrm{ng} / \mathrm{ml}$ and mean blood transfusion units were 12 units. Twelve (17\%) patients were less than 40 years, $4(5 \%)$ of them had RAEB. There were a strong correlation between ferretin and ALT (alanine transaminase) ( $r=0.415 \mathrm{P}: 0.002)$, ferretin and blood units ( $r=0.26 \mathrm{P}: 0.046)$ and negative correlation between ferretin and age ( $r=-0.27 \mathrm{p}: 0.03)$. Forty eight $(70 \%)$ patients were from rural areas. Twenty five $(36 \%)$ males were cigarette smokers. None of the females patients were smokers.

Conclusion: Mean age of presentation of MDS in Egypt is lower than developed countries. Pollution of water and use of insecticides and smoking are high risk factors for MDS among Egyptians while hair dyes and alcohol couldn't be assessed due to cultural reasons. HCV role in pathogenesis of MDS still to be determined. Iron overload is a permanent feature of MDS. The higher mean ALT and ferretin levels and their positive correlation reflect the impact of under treatment of those patients with iron chelation therapy on progression of liver disease.

Keywords: Myelodysplasia; Iron overload; Epidemiology

\section{Introduction}

Myelodysplastic syndromes (MDS) are a heterogeneous group of clonal stem cell disorders which generally occur in older adults but may also affect children. Primary MDS should be distinguished from secondary MDS associated with antineoplastic or immunosuppressive therapy (t-MDS), exposure to toxic compounds, or genetic disorders. The establishment of a neoplastic clone is reflected by dysplastic features and impaired function which may affect all three hematopoietic cell lineages. The ineffective hematopoiesis which causes bone marrow failure is accompanied by peripheral blood cytopenia and is considered to result from increased apoptosis, at least in the less advanced MDS stages [1].

Recent classification of MDS include refractory cytopenia with unilinage dysplasia (refractory anemia, refractory neutropenia, refractory thrombocytopenia), Refractory Anemia with Ring Sideroblast (RARS), refractory cytopenia with multilineage dysplasia (RCMD), Refractory Anemia with Excess Blast-1 (RAEB-1), Refractory anemia with excess blast-2(RAEB-2), myelodysplastic syndrome unclassified(MDS-U), MDS associated with isolated del.(5q) [2].

Over the last decades there has been growing interest in MDS. Because of difficulties in morphological diagnosis and case recording, the epidemiological features of MDS are still poorly defined. Several registries have published data on the regional occurrence of MDS, suggesting that these diseases are more common than previously thought [3].

Although the myelodysplastic syndromes (MDS) are a relatively rare condition, the incidence in the general population is about 5 per 100,000 persons per year. Incidence is linked with age, rising to $20-50$ per 100,000 persons per year in patients older than 60 years of age, and a median age at diagnosis of between 60 and 75 years In Japan, the median age of diagnosis of MDS is 57 years, younger than in Caucasian patients [4].

Other causes of incidence variation among regional studies include small and ill-defined reference populations, bias due to patient referral patterns, expansion and intensity of diagnostic procedures, and different periods of patient recruitment [5].

However, common risk factors for developing MDS include advanced age, male gender, and antecedent exposure to chemotherapy or radiation as treatment for other cancers, which alone accounts for $10 \%$ of MDS cases $[6,7]$.

Smoking is a risk factor for myelodysplastic syndromes especially refractory anemia and for refractory anemia with ringed sideroblasts $[8,9]$.

Occupational exposure to benzene, living near high voltage power lines and house decorating are the risk factors of MDS [10].

Patients with myelodysplastic syndromes (MDS) often require chronic RBC transfusions, which can lead to iron overload. Without

*Corresponding author: Noha M. El Husseiny, Clinical Haematology Unit, Internal Medicine Department, Faculty of Medicine, Cairo University, Egypt, E-mail: Dr_noha2002@yahoo.com

Received March 09, 2012; Accepted April 02, 2012; Published April 09, 2012

Citation: El Husseiny NM, Mohamed SA, Mattar MM (2012) Myelodysplastic Syndrome: An Egyptian Experience. J Blood Disord Transfus 3:121. doi:10.4172/2155-9864.1000121

Copyright: (c) 2012 El Husseiny NM, et al. This is an open-access article distributed under the terms of the Creative Commons Attribution License, which permits unrestricted use, distribution, and reproduction in any medium, provided the original author and source are credited. 
Citation: El Husseiny NM, Mohamed SA, Mattar MM (2012) Myelodysplastic Syndrome: An Egyptian Experience. J Blood Disord Transfus 3:121. doi:10.4172/2155-9864.1000121

Page 2 of 4

adequate management, this may cause progressive damage to hepatic, endocrine, and cardiac organs, significantly affecting overall survival [11].

\section{Aim of the Work}

The present study was designed to analyse clinical, haematological and histomorphogical features in 69 Egyptian myelodysplasic syndrome (MDS) cases.

\section{Patients}

The study had the approval of the Ethical Committee of the Faculty of Medicine-Cairo University. Total of 69 newly diagnosed adult MDS cases registered at Clinical Haematology Unit- Cairo University between 2007 and 2010. Cases were haematologically confirmed and classified according to the FAB/ WHO classification system. Diagnosis of MDS was based on full history taking, clinical assessment and laboratory investigations of complete blood count, Bone marrow aspirate and biopsy, cytogenetic.

\section{Methods}

Files were revised for history of residency, smoking, alcohol intake, immunosuppressive treatment, previous antineoplastic drugs or hair dyes and exposure to insecticides. Complete blood count, ferretin, ALT (alanine transaminase), creatinine, HCV ab, HBsAg were documented. Reports of abdominal ultrasounds were reported.

\section{Statistics}

Statistical analysis was performed using the Statistical Package for the Social Sciences (version 12.0; SPSS, Inc., Chicago, IL, USA). The results are expressed as the mean $\pm \mathrm{SD}$. For dual comparisons, a Student's t-test was used to compare group results. Correlation analysis was performed using the Spearman's test. Differences and correlation were considered as significant at a $\mathrm{p}<0.05$.

\section{Results}

Table 1 summarizes clinical data of the patients. Sixty nine patients

\begin{tabular}{|l|l|}
\hline Parameter & Number of patients $(\%)$ \\
\hline Sex & $39(57 \%)$ females, 30(43\%) male \\
\hline Age & Mean 55 years ( Range 19-95years) \\
\hline $\begin{array}{l}\text { Sural area (documented } \\
\text { usage of fertilizers) }\end{array}$ & 25 males smoke. None of females smokes \\
\hline Hair dyes/Alcohol & None patients $(70 \%)$ \\
\hline $\begin{array}{l}\text { Immunosuppressant / } \\
\text { antineoplastic drugs }\end{array}$ & None \\
\hline HCV +ve & $10(14 \%)$ \\
\hline Abdominal U/S & $\begin{array}{l}10(14 \%) \text { had splenomegaly, one patient with } \\
\text { cirrhotic liver, } 5 \text { (7\%) had hepatomegaly, Rest of } \\
\text { patients has normal US. }\end{array}$ \\
\hline Type of MDS & $\mathbf{1 5}(\mathbf{2 2} \%)$ \\
\hline RA & $\mathbf{3 ( 4 \% )}$ \\
\hline RARS & $\mathbf{2 6 ( 3 8 \% )}$ \\
\hline RCMD & $\mathbf{9 ( 1 3 \% )}$ \\
\hline RAEB-1 & $\mathbf{6}(\mathbf{9} \%)$ \\
\hline RAEB-2 & $\mathbf{1 0 ( 1 4 \% )}$ \\
\hline Hyypoblastic MDS & $\begin{array}{l}\text { All patients were normal karyotyping except } \\
\text { three patients in RAEB-2 had complex cyto- } \\
\text { genetics }\end{array}$ \\
\hline Karyotyping & \\
\hline
\end{tabular}

Table 1: clinical data of patients with MDS.

\begin{tabular}{|l|l|l|}
\hline Parameter & Mean,SD & Range \\
\hline Blood units transfused & $12( \pm 15.6)$ & $0-90$ \\
\hline Haemoglobin $(\mathrm{gm} / \mathrm{dl})$ & $6.8( \pm 1.4)$ & $3.3-10.2$ \\
\hline WBCs $\left(\right.$ cells $\left./ \mathrm{mm}^{3}\right)$ & $4,500( \pm 3,700)$ & $800-17,500$ \\
\hline Platelet count $\left(\mathrm{cell} / \mathrm{mm}^{3}\right)$ & $75,000( \pm 92,794)$ & $3,000-386,000$ \\
\hline ALT $(\mathrm{u} / \mathrm{L})(\mathrm{UNL}: 30 \mathrm{U} / \mathrm{l}$ for men and 20 U/l for women) & $36.1( \pm 40)$ & $8-300$ \\
\hline Creatinin $(\mathrm{mg} / \mathrm{dl})$ & $0.99( \pm 0.55)$ & $0.4-3$ \\
\hline Ferretin $(\mathrm{ng} / \mathrm{ml})$ & $933( \pm 537.77)$ & $89-2700$ \\
\hline
\end{tabular}

Table 2: Laboratory features of the patients.

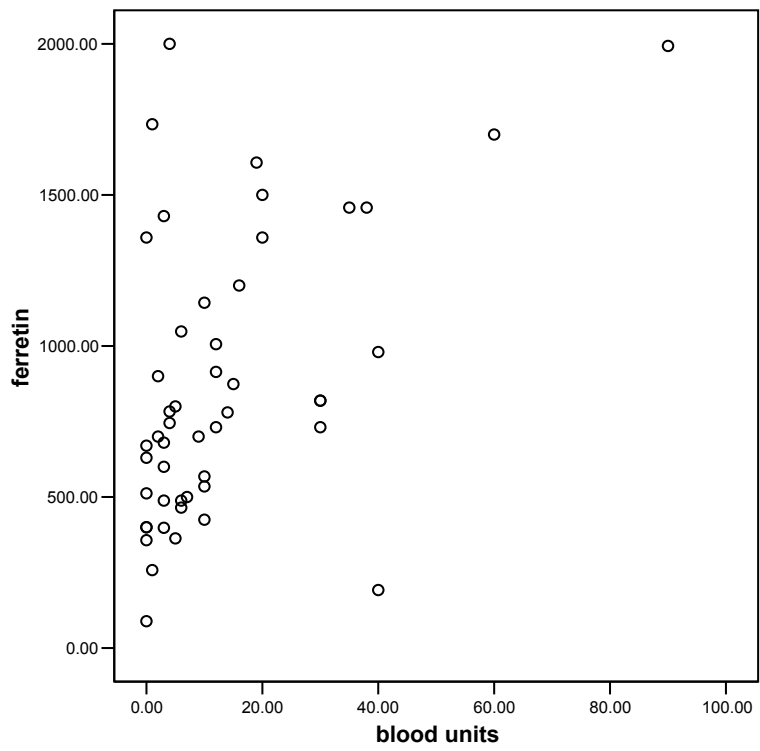

Figure 1: Correlation between ferretin and Blood transfusion.

with MDS were identified. Thirty nine (57\%) females, thirty (43\%) male subjects. Mean age was 55 years. Nine (13\%) patients were positive for HCV. Mean ferretin level was $844 \mathrm{ng} / \mathrm{ml}$ and mean blood transfusion units were 12 units. Table 2 summarizes the laboratory features of the patients. Correlation analysis revealed positive significant correlation between ferretin and blood unit transfusion ( $\mathrm{r}=0.32 \mathrm{P}: 0.03$ ) (Figure 1) and between003ALT and ferretin ( $r=0.32 \mathrm{P}: 0.016$ ) (Figure 2). There is significant difference between $\mathrm{HCV}+\mathrm{ve}$ and non $\mathrm{HCV}$ patients in PLT count $(<0.05)$ but not in ALT, ferretin $(P>0.05)$. Figure 3 represents the percentage of patients affected by each subtype of MDS.

\section{Discussion}

Our study is the first to highlight the demographic features of MDS cases in Egypt through this retrospective study of 69 MDS patients diagnosed in the Clinical Haematology Unit of Cairo University in the period between 2007-2010. Mean age of our patients is 55 years.

Previous studies reported MDS to be a disease of later life, with over half of the reported patients being 70 years or older [12]. In an Indian study of 78 patients with MDS, mean age at presentation was 46.1 years (range: 9 to 82 years) [13]. The median age of occurrence of primary acquired sideroblastic anemia in Romain is 74.4 years, with a range of 12 to 96 years (calculated from 452 cases). Of 445 cases, $60.4 \%$ were male, and $39.6 \%$ female. Not only primary acquired sideroblastic anemia, but the entire myelodysplastic syndrome must be considered as a disease of old age [14]. In a French study of 204 patients with MDS, median age was 70 years and $62 \%$ were males [15]. 
Citation: El Husseiny NM, Mohamed SA, Mattar MM (2012) Myelodysplastic Syndrome: An Egyptian Experience. J Blood Disord Transfus 3:121. doi:10.4172/2155-9864.1000121

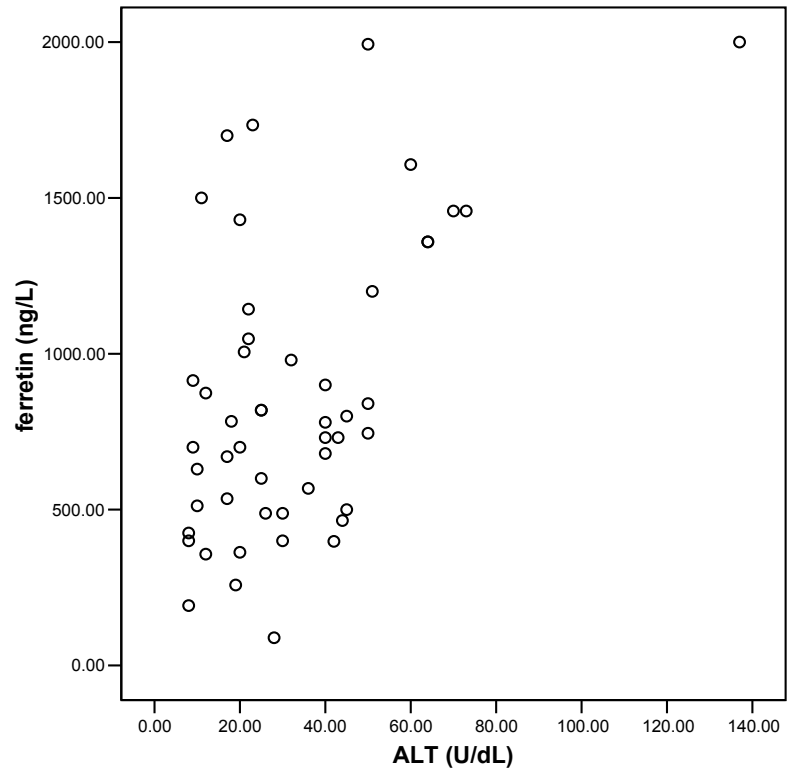

Figure 2: Correlation between ferretin and ALT.

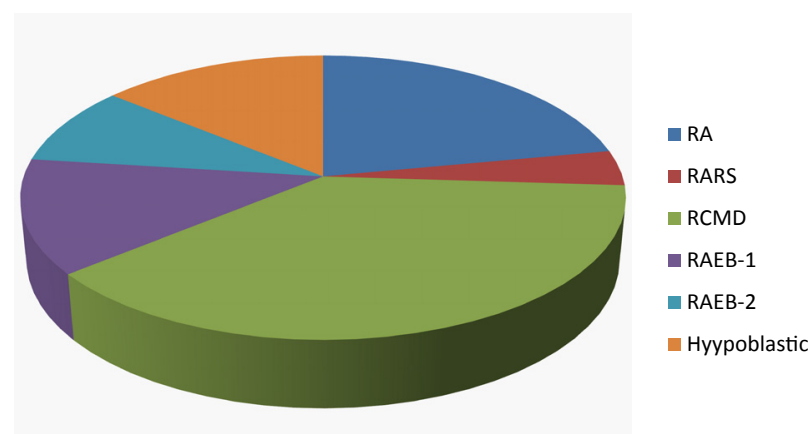

Figure 3: The percentage of each type of MDS in the study. (ALT: alanine transaminase).

12(17\%) patients were less than 40 years, four of them $(5 \%)$ had RAEB. None of them had a previous malignancy or was on immunosuppressant treatment. This is a large percent if compared with other studies of MDS in young age which is considered uncommon in age less than 50 years. It is important to mention that the lowest age reported was 19 years. This is because we are an adult department that admits cases older than 14 years.

One study of 37 MDS patients, 50 years old and younger, represented $6.7 \%$ of the overall study group at one hospital. Another report of 109 adult patients with MDS, 14 (7\%) were reported to be between 28 and 50 years old. Two other large studies of MDS have also included rare patients under the age of 50 [12]

Our data revealed that 48 patients ( $70 \% ; 20$ males and 28 females) were from rural areas mainly Fayum and Bani Sweif with a very well known high index of pollution to water and use of pesticides. This supports the association between being exposed to pesticides, herbicides, or fertilizers and risk of MDS found in some but not all previous studies. This association was found among both men and women though Ciccone et al. reported a statistically significant association with exposure to pesticides only among women [16].
In our study ten patients (14\%) were HCV positive on first diagnosis. Three had RCMD, three had RA, two had RAEB-2, one patient had RARS and one patient with hypoblast MDS.

No clear evidence of a link between HCV and myelodysplasia in literatures. Though there is a strong correlation between HCV and both thrombocytopenia [17] and aplastic anemia [18].

We believe that it is an association rather than a true relation due to high prevalence of HCV among Egyptians [19] and there was no certain type of MDS related to $\mathrm{HCV}$.

Our study revealed significant difference between HCV infected MDS patients and those not infected in PLT count $(\mathrm{p}<0.05)$ but not in ALT or ferretin level $(\mathrm{p}>0.05)$.

In previous studies $\mathrm{HCV}$ infection served as an important and independent correlate of serum ALT level [20]. Mild to moderate hepatic iron loading is common in patients with chronic hepatitis $\mathrm{C}$ [21-23].

The small number of patients infected with $\mathrm{HCV}$ may be the explanation of our data.

There were a strong correlation between ferretin and ALT ( $r=0.415$ $\mathrm{P}: 0.002)$, ferretin and blood units $(\mathrm{r}=0.26 \mathrm{P}: 0.046)$ and negative correlation between ferretin and age $(\mathrm{r}=-0.27 \mathrm{p}: 0.03)$.

Highly significant correlations between serum ferritin concentrations, amount of blood transfused and liver iron concentration has been documented in previous studies [24].

25/30(83.3\%) males were cigarette smokers. None of females patients used to has history of smoking. In a Japanese study, smoking was one of the important risk factors of MDS development [25]. Moreover, There were 10 case-control studies that looked at the association between smoking and MDS, for a total of 1839 cases and 2831 controls. Data strongly suggested that smoking was significantly associated with MDS. The meta-estimate for the association between ever smoking and MDS was 1.45 (95\% CI: 1.21-1.74), with heterogeneity among studies $(p=0.05)$, but no evidence of publication bias [26]. Relation was related to duration and intensity of smoking as well as a decrease in the risk few years after stoppage of smoking [27].

Ten patients were cigarette smokers and coming from polluted areas. Their diagnosis were 7 with RAEB I,II and 3 with RCMD.

None were on immunosuppressants or antineoplastic treatment before onset of disease.

Our study showed that number of males was $30(43 \%)$ while females were 39 (57\%). Previous studies reported that male sex is a risk factor for MDS $[6,7]$.

In conclusion the mean age of presentation of MDS in Egypt is lower than developed countries. Pollution of water and use of insecticides and smoking are high risk factors for MDS among Egyptians while hair dyes and alcohol couldn't be assessed due to cultural reasons. HCV role in pathogenesis of MDS still to be determined.

\section{References}

1. Schmitt-Graeff A, Mattern D, Köhler H, Hezel J, Lübbert M (2000) Myelodysplastic syndromes (MDS). Aspects of hematopathologic diagnosis. Pathologe 21: 1-15.

2. Swerdlow SH, Campo E, Harris NL, Jaffe ES, Pileri SA, et al. (2008) World health organization classification of tumors of haematopoietic and lymphoid tissues, IARC Press, Lyon. 
Citation: El Husseiny NM, Mohamed SA, Mattar MM (2012) Myelodysplastic Syndrome: An Egyptian Experience. J Blood Disord Transfus 3:121. doi:10.4172/2155-9864.1000121

3. Carlo Aul (1998) Epidemiology of Myelodysplastic Syndromes. Abstracts from the Corporate Friday symposium "MDS: Epidemiology, Molecular Biology, Pathology, and Innovations in Treatment," American Society of Hematology meeting, Miami, Florida.

4. Gattermann N (2008) Overview of guidelines on iron chelation therapy in patients with myelodysplastic syndromes and transfusional iron overload. Int J Hematol 88: 24-29.

5. Aul C, Giagounidis A, Germing U (2001) Epidemiological features of myelodysplastic syndromes: results from regional cancer surveys and hospitalbased statistics. Int J Hematol 73: 405-410.

6. Sekeres MA (2011) Epidemiology, Natural History, and Practice Patterns of Patients with Myelodysplastic Syndromes in 2010. J Natl Compr Canc Netw 9: 57-63.

7. Sekeres MA (2010) The epidemiology of myelodysplastic syndromes. Hematol Oncol Clin North Am 24: 287-294.

8. Du Y, Fryzek J, Sekeres MA, Taioli E (2010) Smoking and alcohol intake as risk factors for myelodysplastic syndromes (MDS). Leuk Res 34: 1-5.

9. Ma X, Lim U, Park Y, Mayne ST, Wang R, et al. (2009) Obesity, lifestyle factors, and risk of myelodysplastic syndromes in a large US cohort. Am J Epidemio 169: $1492-1499$

10. Lv L, Lin GW, Wang XQ, Bao LM, Zou HJ (2007) A case-control study of risk factors for myelodysplastic syndromes. Zhonghua Lao Dong Wei Sheng Zhi Ye Bing Za Zhi 25: 705-709.

11. Jabbour E, Garcia-Manero G, Taher A, Kantarjian HM (2009) Managing Iron Overload in Patients with Myelodysplastic Syndromes with Oral Deferasirox Therapy. Oncologist 14: 489-496.

12. Chang KL, O'Donnell MR, Slovak ML, Dagis AC, Arber DA, et al. (2002) Primary myelodysplasia occurring in adults under 50 years old: a clinicopathologic study of 52 patients. Leukemia 16: 623-631.

13. Kar R, Rao S, Saxena R (2009) Myelodysplastic syndromes: classification and prognostic scoring systems and their applicability in Indian scenario-experience from a tertiary care center. Hematology 14: 145-149.

14. Hadnagy C (1991) Primary acquired sideroblastic anemia and myelodysplastic syndrome from a geriatric point of view. Z Gerontol 24: 105-109.

15. Nisse C, Haguenoer JM, Grandbastien B, Preudhomme C, Fontaine B, et al.
(2001) Occupational and environmental risk factors of the myelodysplastic syndromes in the North of France. Br J Haematol 112: 927-935.

16. Strom SS, Gu Y, Gruschkus SK, Pierce SA, Estey EH (2005) Risk factors of myelodysplastic syndromes: a case-control study. Leukemia 19: 1912-1918.

17. García-Suárez J, Burgaleta C, Hernanz N, Albarran F, Tobaruela P, et al. (2000) HCV-associated thrombocytopenia: clinical characteristics and platelet response after recombinant $\alpha 2 b$-interferon therapy. $\mathrm{Br} J$ Haematol 110: 98 103.

18. Brown KE, Tisdale J, Barrett AJ, Dunbar CE, Young NS (1997) HepatitisAssociated Aplastic Anemia. N Engl J Med 336: 1059-1064.

19. Waked IA, Saleh SM, Moustafa MS, Raouf AA, Thomas DL, et al. (1995) High prevalence of hepatitis $C$ in Egyptian patients with chronic liver disease. Gut 37: 105-107.

20. Hsu CS, Liu CJ, Liu CH, Chen CL, Lai MY, et al. (2008) Metabolic profiles in patients with chronic hepatitis C: a case-control study. Hepatol Int 2: 250-257.

21. Tung BY, Emond MJ, Bronner MP, Raaka SD, Cotler SJ, et al. (2003) Hepatitis C, iron status, and disease severity: Relationship with HFE mutations. Gastroenterology 124: 303-317.

22. Takikawa T, Hayashi H, Nishimura N, Yano M, Isomura T, et al. (1994) Correlation between serum levels of alanine aminotransferase and ferritin in male blood donors with antibody to hepatitis C virus. J Gastroenterol 29: 593597.

23. Arber N, Konikoff FM, Moshkowitz M, Baratz M, Hallak A, et al. (1994) Increased serum iron and iron saturation without liver iron accumulation distinguish chronic hepatitis $\mathrm{C}$ from other chronic liver diseases. Dig Dis Sc 39: 2656-2659.

24. Cazzola M, Borgna-Pignatti C, de Stefano P, Bergamaschi G, Bongo IG, et al. (1983) Internal Distribution of Excess Iron and Sources of Serum Ferritin in Patients with Thalassaemia. Scand J Haematol 30: 289-296.

25. Ido M, Nagata C, Kawakami N, Shimizu H, Yoshida Y, et al. (1996) A casecontrol study of myelodysplastic syndromes among Japanese men and women. Leuk Res 20: 727-731.

26. Du Y, Fryzek J, Sekeres MA, Taioli E (2010) Smoking and alcohol intake as risk factors for myelodysplastic syndromes (MDS). Leuk Res 34: 1-5.

27. Björk J, Albin M, Mauritzson N, Strömberg U, Johansson B, et al. (2000) Smoking and myelodysplastic syndromes. Epidemiology 11: 285-291. 